\title{
Specialized Synapse-Associated Structures within the Calyx of Held
}

\author{
Kevin C. Rowland, ${ }^{1,3}$ Nancy K. Irby, ${ }^{2,3}$ and George A. Spirou ${ }^{1,2,3}$ \\ Departments of ${ }^{1}$ Physiology and ${ }^{2}$ Otolaryngology, and ${ }^{3}$ Sensory Neuroscience Research Center, West Virginia University \\ School of Medicine, Morgantown, West Virginia 26506-9200
}

The calyx of Held exhibits fast glutamatergic neurotransmission at high rates with low temporal jitter and has adapted specialized synaptic mechanisms to support its functional demands. We report the presence in calyces of an atypical arrangement of subcellular organelles, called the mitochondria-associated adherens complex (MAC). We demonstrate that MACs are located adjacent to synapses and contain membranous elements linked with coated and uncoated vesicles. Mitochondria that form MACs have more complex geometries than other mitochondria within the calyx and can extend between clusters of synapses. We estimate that the calyx contains 1600 MACs, 2400 synapses, and 6200 readily releasable vesicles. We also identify synaptic vesicle endocytotic regions close to MACs and synapses and hypothesize that calyces are composed of multiple activity modules, each containing machinery for vesicle release and recycling.

Key words: auditory brainstem; calyx of Held; mitochondria; punctum adherens; synapse; synaptic vesicle recycling
The calyx of Held is one of the largest nerve terminals in the CNS (Held, 1893). Along with large and modified end-bulbs of Held delivered by auditory nerve fibers onto cochlear nucleus neurons (Cant and Morest, 1979; Tolbert and Morest, 1982; Fekete et al., 1984), these complex nerve terminals are key elements in brainstem circuitry that subserves sound localization (Morest, 1968). Spontaneous activity (generated in the absence of sound) can exceed 100 spikes/sec at the calyx terminal, and sound-driven activity at the most sensitive frequency of the calyceal neuron can approach 600 spikes/sec (Spirou et al., 1990). Temporal synchrony of calyceal neurons to a preferred phase of a low-frequency sound exceeds that found in the auditory nerve, and it can entrain (fire on every cycle of the stimulus sinusoid) at rates approaching $1 \mathrm{kHz}$ (Joris et al., 1994a,b).

High activity rates place demands on endocytotic mechanisms to maintain a pool of releasable vesicles. Some neurons, such as retinal bipolar cells, possess specialized structures called synaptic ribbons that are involved in vesicle trafficking, and therefore have unique mechanisms to solve their demands for synaptic activity (von Gersdorff and Matthews, 1999). It is plausible that the calyceal terminal, because of its extremely high spike rate and the temporal precision required to accomplish its task of sound localization, also uses unique structures and mechanisms.

A noteworthy arrangement of organelles, consisting of a mitochondrion located near the presynaptic membrane and tethered via filaments to a punctum adherens, was first described in nerve terminals of the spinal cord (Gray, 1963). In the auditory system, this structure was noted in large and modified end-bulbs of auditory nerve fibers (Cant and Morest, 1979; Tolbert and Morest, 1982). More recently, we described this structure, which we named the mitochondria-associated adherens complex (MAC), in large collateral terminals of calyceal axons that are found in the superior olivary complex (Spirou et al., 1998). Given the diversity of cellular elements that comprise the $\mathrm{MAC}$, it could perform various func-

Received Aug. 2, 2000; revised Oct. 6, 2000; accepted Oct. 9, 2000.

This work was supported by National Science Foundation Grant IBN 9728933. We thank Albert Berrebi for expertise in PEP-19 immunocytochemistry, Brian Pope and Marcia Feinberg for technical assistance, and Erika Hartweig for training in the collection of serial sections. We thank members of the Sensory Neuroscience Research Center, William Wonderlin, and Philip Smith for critical review of this manuscript, Peter Mathers for insightful discussions of data, and George Augustine for reading an earlier version of this paper.

Correspondence should be addressed to Dr. George A. Spirou, Box 9200, Department of Otolaryngology, West Virginia University School of Medicine, Morgantown, WV 26506-9200. E-mail: gspirou@wvu.edu.

Copyright (C) 2000 Society for Neuroscience $0270-6474 / 00 / 209135-10 \$ 15.00 / 0$ tions in the nerve terminal, including calcium buffering, supplying energy for synaptic vesicle fusion and recycling, processing recycled vesicle membrane, and cell adhesion. The presence of MACs in other large terminals of the auditory brainstem prompted our investigation of their presence in calyceal terminals and a more detailed examination of their structure and relationship to synapses. In this report, we reveal an intertwined spatial arrangement of MACs and synaptic structures and offer several hypotheses about possible functions of the structural components of the MAC in synaptic transmission.

\section{MATERIALS AND METHODS}

Five adult cats were used in this study. Three cats were processed for electron microscopy and two cats were processed for PEP-19 immunocytochemistry. All animals were deeply anesthetized by an intramuscular injection of xylazine $(2 \mathrm{mg} / \mathrm{kg})$ and ketamine $(10 \mathrm{mg} / \mathrm{kg})$, followed by a pentobarbital injection $(40 \mathrm{mg} / \mathrm{kg}$, i.v.), before transcardial perfusion. The protocol used for PEP-19 immunocytochemistry is described elsewhere (Berrebi and Mugnaini, 1991; Spirou and Berrebi, 1996; Berrebi and Spirou, 1998) and is summarized briefly here.

Immunocytochemistry. Two animals were perfused transcardially with $0.9 \%$ saline solution, followed by 11 of fixative ( $4 \%$ formaldehyde, $0.5 \%$ zinc dichromate, $0.1 \%$ glutaraldehyde in $0.75 \%$ saline, $\mathrm{pH} 4.8$ ), then by 11 of the same fixative with glutaraldehyde removed. Brains were dissected after $1 \mathrm{hr}$ and immersed in 30\% sucrose in saline for cryoprotection. After cryoprotection, frozen sections taken at 25-40 $\mu \mathrm{m}$ thickness were immersed in blocking and detergent solution for $1 \mathrm{hr}(5 \%$ normal donkey serum, $0.5 \%$ Triton X-100 in $0.5 \mathrm{M}$ Tris buffer). Sections were incubated in rabbit polyclonal antiserum to PEP-19 protein (diluted to 1:2000 in 1\% normal donkey serum and $0.1 \%$ Triton X-100), which was revealed by using the standard Elite avidin-biotin peroxidase method (Vector Laboratories, Burlingame, CA) or the peroxidase/anti-peroxidase method (Sternberger, 1979).

Electron microscopy. The animals used for electron microscopy were perfused transcardially with an initial calcium-free Ringer's solution followed by a mixture of $2 \%$ paraformaldehyde and $2.5 \%$ glutaraldehyde in $0.1 \mathrm{~m}$ phosphate buffer. The brainstem was cut into $150 \mu \mathrm{m}$ sections in the coronal plane, post-fixed with osmium tetroxide $(0.5 \%)$, and stained en bloc with aqueous uranyl acetate $(2 \%)$, dehydrated, and flat-embedded in Epon. Tissue containing the medial nucleus of the trapezoid body (MNTB), which is innervated by calyces of Held, was re-embedded and trimmed for cutting ultrathin sections $(60-70 \mathrm{~nm})$. Sequential sections were collected and stained with $0.5 \%$ uranyl acetate and $3 \%$ lead citrate using an automatic grid stainer (Leica, Nussloch, Germany).

Construction of en face diagrams. Individual calyces of Held were tracked in serial ultrathin sections and photographed by using a Jeol 1010 electron microscope at $80 \mathrm{kV}$ with magnifications of $4,000-20,000 \times$. To create en face diagrams, presynaptic membranes and mitochondria were traced from electron micrographs onto transparencies and coded as either synaptic junctions or punctum adherens. Marks for registration of serial sections were added to the tracing by visual determination of the best alignment of all mitochondria on adjacent sections. Synapses were identified as clusters of synaptic vesicles directly associated with dense projections of the presynaptic membrane. Punctum adherens were identified by 
symmetrically distributed membrane densities without association of synaptic vesicles. Tracings of the coded presynaptic membrane were scanned into a computer and measured using NIH Image. Total surface areas of synaptic junctions and puncta adherentia were calculated by summing their lengths on individual sections and by multiplying by the section thickness. En face diagrams were created by mapping the location of synapses and punctum adherens relative to register marks (as measured in NIH Image) using graphing software (Excel, Microsoft). The locations of the vesicular chain or mitochondrial plaque of each MAC were plotted on the en face diagram by placing a symbol over its corresponding punctum adherens. Distances from the edges of the vesicular chain or mitochondrial plaque to the nearest synapse were measured on the en face diagram by using NIH Image. Data are reported as mean \pm SD unless indicated otherwise.

Mitochondria morphology. To create three-dimensional models of mitochondria, electron micrographs were scanned and imported into software for alignment of serial sections (Align, Kristen Harris), and outlines of the mitochondria were marked using software (Trace, Kristen Harris; synapses.bu.edu). Virtual reality modeling language files were created (Trace) and viewed with a three-dimensional graphics program (Amapi3D, TGS).

\section{RESULTS}

\section{The calyx of Held is organized into distinct segments}

The calyx of Held is a complex nerve terminal composed of numerous branches linked to swellings of various sizes that, in composite, envelope the postsynaptic cell body. A camera lucida drawing of a calyx and a photomicrograph through a single focal plane (Fig. $1 A$, inset) are shown in Figure $1 A$. Leading to the calyx is a large axon, $5-10 \mu \mathrm{m}$ diameter in cats, which at the base of the terminal branches into two to four thick stalks (each 3-5 $\mu \mathrm{m}$ diameter; labeled st in Fig. $1 A, B$ ) that extend along the postsynaptic cell body surface to the opposite pole of the cell (Fig. 1B). These stalks usually terminate abruptly, but give rise along their distance to thin processes termed necks (Lenn and Reese, 1966) (labeled $n$ in Fig. $1 A, E$ ), which connect in series to large and small swellings (labeled $s w$ in Fig. $1 A, E$ ). The necks have varying lengths $(2.83 \pm 2.0 \mu \mathrm{m} ; n=70)$ but a relatively consistent diameter of $\sim 1$ $\mu \mathrm{m}(0.99 \pm 0.42 \mu \mathrm{m} ; n=70)$.

Synaptic junctions are found in the calyceal stalks and swellings. Numerous zones containing synapses alternate along the entire length of the stalks with regions where the presynaptic and postsynaptic membranes separate (Fig. $1 B$, asterisks; boxed area amplified in $D$ ). Synaptic junctions are also formed with somatic appendages (labeled $s a$ in Fig. $1 B$ ) that extend away from the cell body along the sides and end of each stalk. Synaptic junctions are rarely found on the side of the stalk that faces away from the postsynaptic cell body. That side of the stalk is usually apposed to glial processes and myelinated axons. The same arrangement of synapses is found in large and small swellings (data not shown). Necks are not in apposition to the postsynaptic surface, contain neurofilaments, are unmyelinated, and lack synaptic junctions (Fig. 1E).

Regions of apposition of the presynaptic and postsynaptic membranes contain not only synaptic junctions but also specialized organelle assemblies that we have named the MAC (Fig. 1C) (Spirou et al., 1998). The key elements of this structure are a punctum adherens $(p a)$, thought to attach the membranes of two cells, tethered via filaments $(f)$ that extend $\sim 180 \mathrm{~nm}(179 \pm$ $12.7 \mathrm{~nm} ; n=26$ ) away from the membrane to a dense plaque called the mitochondrial plaque $(\mathrm{mp})$, which is oriented parallel to the membrane and subjacent to a mitochondrion. The mitochondrial surface is typically flattened where it faces the mitochondrial plaque, and its cristae are oriented perpendicular to its flattened surface. Within the filaments are found membranous structures that are tubular or vesicular in appearance, called the vesicular chain [ $v c$, after Tolbert and Morest (1982)]. MACs are common elements within the calyx, and in many individual ultrathin sections are often located adjacent to synapses (Fig. 1D). Their apparent proximity to synapses and associations with membranous, often vesicular structures are suggestive of a role for MACs in synaptic function.

\section{The adjacency of mitochondria-associated adherens complexes and synapses is revealed by serial section electron microscopy}

To determine the spatial association between MACs and synapses, serial ultrathin sections $(60-70 \mathrm{~nm})$ of the MNTB, where calyces of Held are located, were collected and processed for electron microscopy. Representative serial sections from a small swelling are pictured in Figure $2 A-E$. In $A$, a MAC $(M 1)$ with its mitochondrion $(m 1)$, mitochondrial plaque, vesicular chain $(v c)$, filaments, and punctum adherens is located at the left portion of the swelling. The vesicular chain of MAC-M1 $(A-C)$ is composed of vesicular and tubular membranes. A synapse $(B-E, s 1)$ lies adjacent to MAC-M1. The dense projections of s1, thought to represent vesicle-docking sites, are evident in Figure $2 C-E$. Mitochondrion $\mathrm{m} 1$ forms a second MAC in the three sections after Figure $2 E$ (data not shown). The region of cell membrane containing MAC-M1 and s1 at the left part of the swelling is isolated by a region of wide separation between the presynaptic and postsynaptic membrane from another region, in the middle of the swelling, which contains another MAC (M2) and synapse (s2). These enlarged spaces have been noted in calyces of several species [rat, Lenn and Reese (1966); bat, Nakajima (1971), Petelina (1975); cat, Jean-Baptiste and Morest (1975), Casey and Feldman (1985)] and are called extended extracellular spaces (EESs) (Fig. 2, asterisks). MAC-M2 exhibits a more complex arrangement of vesicular and tubular membrane (Fig. $2 B-D$ ) that merges with a group of synaptic vesicles, some of which are associated with dense projections of s2 (Fig. 2C-E). The middle region of the swelling is separated by another EES from a third region of membrane apposition at the right of the swelling. This MAC (M3) also partly overlies its adjacent synapse (Fig. $2 C-E, s 3$ ). Therefore, the spatial relationship between MACs and synapses is complex and is best revealed by mapping the location of MACs and synapses on the presynaptic membrane surface.

Maps indicating the location of MACs and synapses were made in the swelling and stalk compartments of the calyx (Fig. 3A,B). Densities of the presynaptic and postsynaptic membrane, when viewed using magnification of at least $4000 \times$, could be classified as synapse or punctum adherens regions of MACs. Electron micrographs were scanned into a computer and aligned, and the membrane areas occupied by synapses and MACs were coded in dark gray and black, respectively. The membrane of the nerve terminal that did not face the postsynaptic cell was not included in the analysis, and the remaining membrane was unfolded into a flat sheet. The resulting en face maps revealed that MACs and synapses formed clusters that were separated by large distances. Inspection of the composite electron micrographs revealed that nonMAC or synapse-containing membrane (coded in light gray) was primarily occupied by the EES. In the en face map of the swelling shown in Figure $3 A$, the clusters were composed of MACs forming a core surrounded by synapses, except at the periphery of the swelling where synapses were found without associated MACs. Inspection of the composite micrographs revealed that these were regions along the side of the swellings that faced somatic appendages of the MNTB cell. An intertwined arrangement of MACs and synapses was also found in stalks (Fig. 3B). Here, MACs were interspersed with synapses and found in regions that apposed somatic appendages (Fig. 3B, right side).

The adjacency of MACs and synapses was quantified by measuring the distance, on the en face diagram, from the vesicular chain or mitochondrial plaque portion of the MAC (Fig. $3 A, B$, small white circles) to the nearest synapse. The mean distance from these components of the MAC to the edge of the nearest synapse was $202 \pm 94.9 \mathrm{~nm}$, or approximately five synaptic vesicle diameters (Fig. 3C). However, the distance from some synapses to the nearest MAC could approach $1 \mu \mathrm{m}$ (Fig. $3 D$ ), consistent with the absence of MACs in some regions of membrane apposition (Fig. $3 A$ ). These distances were measured from five series of sections taken from four calyces in two animals, each having a composite thickness of 1.3-4.8 $\mu \mathrm{m}$. The same spatial relationship between MACs 

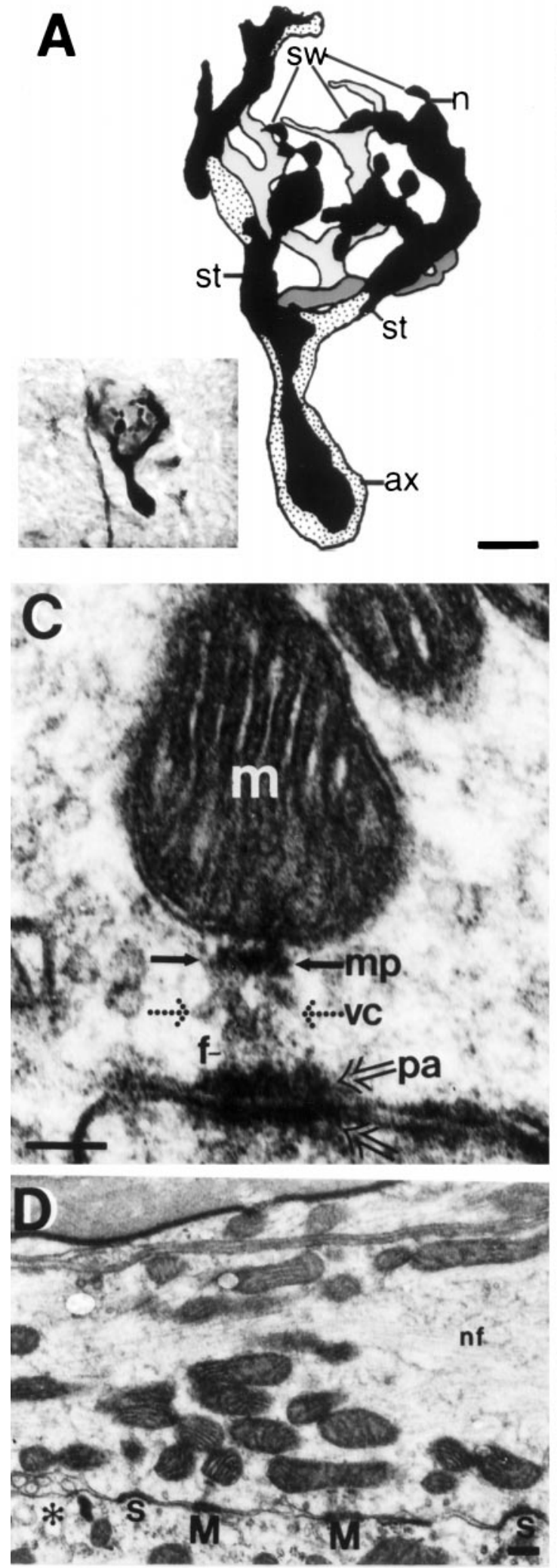
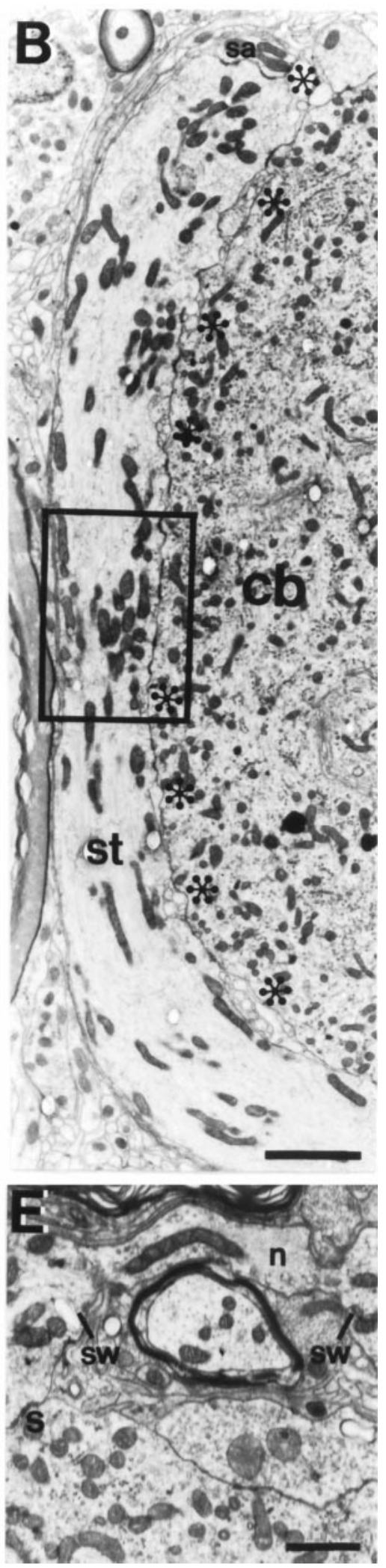

Figure 1. The calyx of Held is a large, complex nerve terminal that envelops the postsynaptic neuron and has multiple synaptic sites. $A$, Camera lucida and light micrograph (inset) of a calyx revealed by antibodies against the putative calcium binding protein PEP-19. The calyceal axon $(a x)$ branches into four stalks (st, two of which are labeled), which themselves branch through narrow necks $(n)$ of varying length into bulb-shaped swellings $(s w)$ of various sizes. Black and stippled areas represent more superficial focal planes than light and dark gray areas. Scale bar, $5 \mu \mathrm{m}$. $B$, Electron micrograph of a stalk $(s t)$ portion of the calyx of Held that wraps halfway around the MNTB cell body $(c b)$. Regions of close apposition between presynaptic and postsynaptic membrane alternate with regions of wide separation, called the EES (next to asterisks). The end of the stalk contacts a somatic appendage (sa). Boxed region is shown in $D$. Scale bar, $2 \mu \mathrm{m}$. $C$, Elements of the MAC: mitochondrion $(m)$, mitochondrial plaque ( $m p$, solid arrows), filaments $(f)$, punctum adherens ( $\mathrm{pa}$, open arrows), and vesicular chain ( $v c$, dotted arrows). Scale bar, $100 \mathrm{~nm}$. $D$, Electron micrograph of the boxed outline in $B$ reveals mitochondria surrounding a central core of neurofilaments $(n f)$. Synapses $(s)$ and MACs $(M)$ are interspersed along the stalk and occupy most of the regions of apposition between presynaptic and postsynaptic membranes. Asterisk underlies the extended extracellular space. Scale bar, $250 \mathrm{~nm}$. E, Electron micrograph of a neck $(n)$ that connects two swellings ( $s w$ ), the latter of which contains synapses $(s)$. Scale bar, $1 \mu \mathrm{m}$. and synapses was also evident in another five reconstructions, taken from five calyces (four of which are from a third animal), each having a composite thickness of at least $0.5 \mu \mathrm{m}$.

Construction of en face diagrams from serial sections affords the opportunity to estimate the number of synapses and MACs in each calyx of Held. In each en face diagram, individual synapses and puncta adherentia were outlined, and their surface area was calculated by summing the lengths measured from the micrographs and then multiplying by the section thickness. The average sizes for each en face diagram are reported in Table 1. Overall, synaptic junction surface area averaged $70,079 \mathrm{~nm}^{2}$ and occupied $11.6 \%$ of the presynaptic membrane surface, whereas MACs surface area averaged $54,622 \mathrm{~nm}^{2}$ and occupied $5.8 \%$ of the presynaptic membrane surface. The postsynaptic MNTB cell body is nearly spherical in shape and $\sim 35 \mu \mathrm{m}$ in diameter. Using published measurements that the calyx covers on average $38 \%$ of the postsynaptic cell 


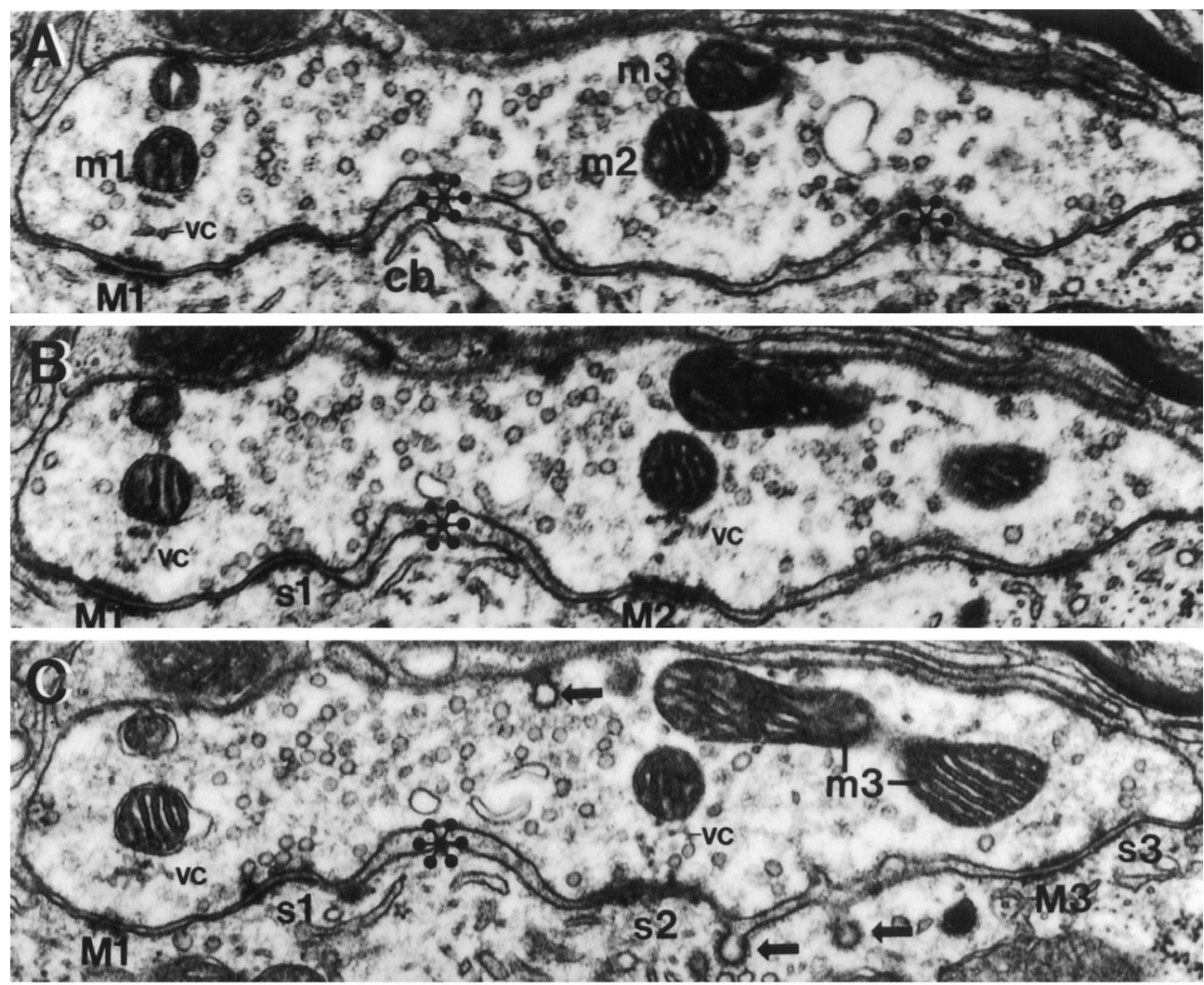

Figure 2. Serial sections indicate that MACs are adjacent to synapses. These serial sections of a swelling in contact with an MNTB cell body $(c b)$ reveal three regions of membrane apposition (left, middle, and right) separated by an EES (asterisks; rightmost EES is only marked in $A$ ). Three MACs $(M 1, A-C ; M 2, B ; M 3, C-E)$ and their associated mitochondria $(\mathrm{ml}$, $m 2$, and $m 3$ in $A ; m 3$ labeled again in $C$ ) and vesicular chain $(v c)$ are adjacent to synapses $(s 1, s 2$, and $s 3)$. Large coated vesicles are budding from the side of the terminal facing away from the MNTB cell and postsynaptically from the extended extracellular space $(C, D$, solid arrows). Bumps in the presynaptic membrane $(E$, open arrows) at the synapse could indicate vesicle fusion or retrieval sites. A coated vesicle $(E$, solid arrow) is located adjacent to the presynaptic membrane. Scale bar (shown in $E$ for $A-E$ ): $200 \mathrm{~nm}$.

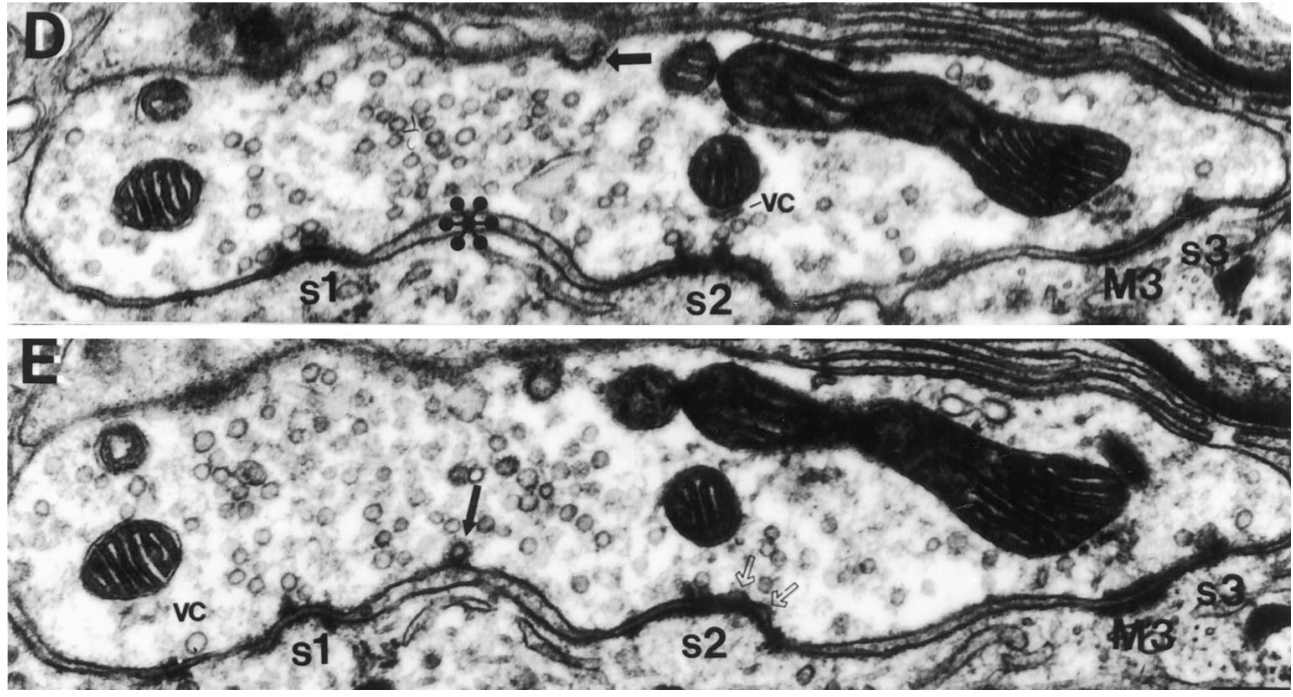

body in cats [our calculation from Smith et al. (1991, 1998)], we estimate that the calyx of Held contains $\sim 2400$ synaptic junctions and 1600 MACs. The number of synapses is larger than that estimated for large synaptic end-bulb terminals in the ventral cochlear nucleus (Ryugo et al., 1996).

\section{Vesicular and tubular membrane structures in the nerve terminal}

Arrangements of membrane within the MAC can take the form of two to four linked vesicular structures or, more commonly, of combinations of tubular and vesicular membrane that can extend along the sides of the mitochondrion away from the cell membrane (Fig. 4F, dotted arrow). The tubular networks are curved and branched, have a twisted appearance, and appear to be fused or in the process of budding round vesicles that are the size of synaptic vesicles (Fig. 4B,E,F, arrowheads). Some membranous structures are non-round, with profiles that are approximately the size of synaptic vesicles (vesicular chain of M1 in Figs. $2 A$ and $4 E$ ).
Coated vesicles in the nerve terminal, presumably recaptured from the presynaptic membrane, are the same size as synaptic vesicles and can be found in proximity to and fused to tubular networks associated with MACs (Figs. $2 E, 4 A, C$, solid arrows). Coated vesicles appear to emerge from synaptic zones or adjacent areas of presynaptic membrane (Fig. $4 A, F$, open arrows). Synaptic zones also contain structures that could represent vesicle fusion sites or the early stages of vesicle reuptake (Fig. $2 E$, open arrows at s2). The EES appears to be a common site of membrane recycling (Figs. 2C, 4D, open arrows), as originally observed using scanning (freeze-fracture) and transmission electron microscopy (Heuser and Reese, 1973; Gulley et al., 1978). All areas of the presynaptic nerve terminal membrane seem capable of endocytotic events, so we measured the prevalence of coated pits, presumably representing endocytosing vesicles, in different regions of the presynaptic membrane. Most coated pits were found immediately adjacent to the synapse $(27 \%)$ or at the edge of the EES (42\%). Large endo- 


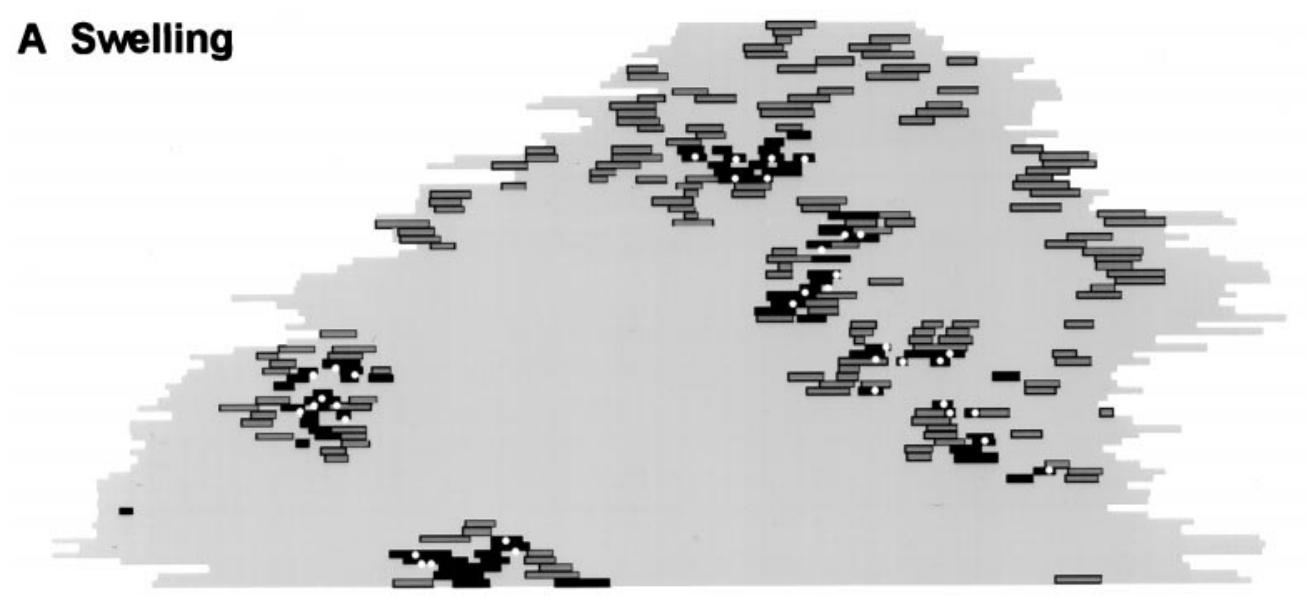

B Stalk

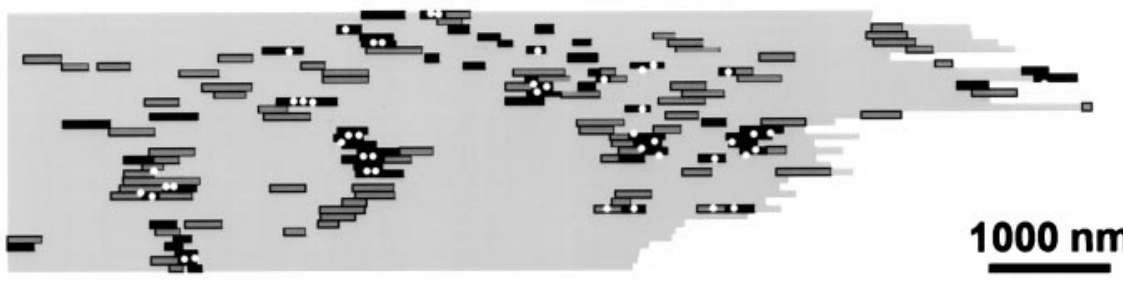

C

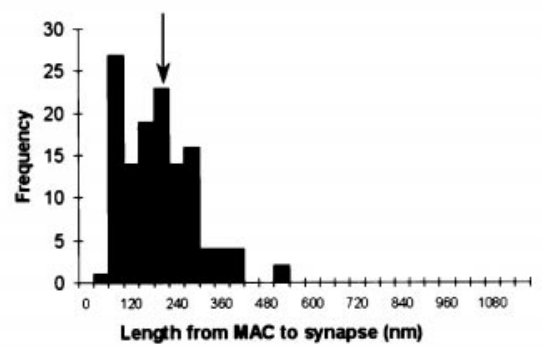

D

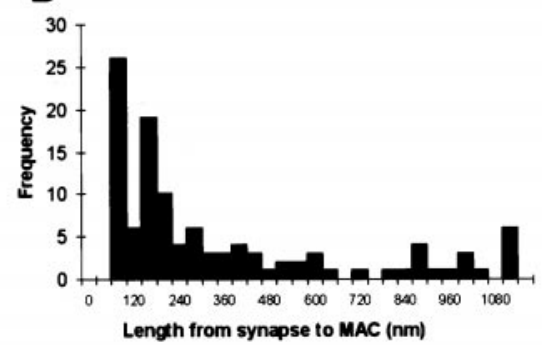

Figure 3. The interdigitated spatial relationship of synapses and MACs is revealed in en face views of the flattened presynaptic membrane. Lengths of membrane that contain synapses are coded dark gray, and punctum adherens components of MACs are coded black. Other regions of membrane, primarily composed of extended extracellular space, are coded light gray. Small white circles represent the vesicular chain and mitochondrial plaque components of MACs. A, En face diagram through one swelling portion of a calyx (77 serial sections). $B$, En face diagram through one stalk portion of a calyx (36 serial sections). $C$, The shortest distance from the mitochondrial plaque or vesicular chain components of MACs to synapses averaged $202 \pm 94.9 \mathrm{~nm}$ (arrow). D, The shortest distance from synapses to the nearest MAC often could exceed $500 \mathrm{~nm}$, reflecting a category of synapses that are not located near MACs (as shown in $A$ ).

Table 1. Presynaptic membrane specializations in the calyx of Held

Synaptic junction

\begin{tabular}{|c|c|c|c|c|}
\hline \multirow[b]{2}{*}{$\begin{array}{l}\text { Calyx } \\
\text { of Held }\end{array}$} & \multicolumn{2}{|l|}{ Synaptic junction } & \multicolumn{2}{|l|}{ Punctum adherens } \\
\hline & $\begin{array}{l}\text { Average surface area of } \\
\text { synaptic junctions } \\
\left(\mathrm{nm}^{2}\right)\end{array}$ & $\begin{array}{l}\text { Percent of total pre- } \\
\text { synaptic membrane }\end{array}$ & $\begin{array}{l}\text { Average surface area of } \\
\text { punctum adherens } \\
\left(\mathrm{nm}^{2}\right)\end{array}$ & $\begin{array}{l}\text { Percent of total pre- } \\
\text { synaptic membrane }\end{array}$ \\
\hline 1 & 78,651 & 12.1 & 64,512 & 5.7 \\
\hline 1 & 76,300 & 9.6 & 58,240 & 6.0 \\
\hline 2 & 56,264 & 15.0 & 28,523 & 9.6 \\
\hline 3 & 69,835 & 9.0 & 83,843 & 3.2 \\
\hline 4 & 69,348 & 12.2 & 37,996 & 4.5 \\
\hline Average & $70,079 \pm 3,896^{a}$ & 11.6 & $54,622 \pm 9,803^{a}$ & 5.8 \\
\hline
\end{tabular}

${ }^{a}$ Results are mean \pm SEM; four calyces of Held from two animals were analyzed. Top entry taken from analysis of a stalk, calyx 4 from a stalk or large swelling, and remaining entries from swellings.

cytotic coated pits and vesicles are often located post-synaptic to the EES or associated with membrane that faces away from the MNTB cell and are probably not involved in synaptic vesicle recycling (Fig. 2C, solid arrows). On the basis of the presence of MAC and synapse-containing regions of membrane apposition, flanked by EES and endocytotic profiles, we propose that the calyx is composed of numerous activity modules, each with a selfcontained system of vesicle recycling.

\section{Are there subpopulations of mitochondria in the calyx of Held?}

Mitochondria that form MACs have structural specializations in the precise orientation of their cristae and flattened edge where they abut the mitochondrial plaque. The branched and curving appearance of mitochondria in individual electron micrographs (Fig. 2, m3) was suggestive that MAC-forming mitochondria were more complex structurally than other mitochondria in the nerve terminal. To investigate this hypothesis, mitochondria were reconstructed across serial sections, and their complexity was determined by counting the number of tips, or ends, of processes. For example, the electron micrograph in Figure $5 A$ reveals what appear to be four presynaptic mitochondria. In the next two sections in the series (Fig. 5B,C), three of the profiles (labeled $m$ in Fig. 5A) merge into a single mitochondrion. Three-dimensional reconstruction of this mitochondrion (Fig. $5 D, E$ ) reveals the three limbs seen in the serial sections (labeled $m$ ). The mitochondrion has four tips 
Figure 4. Coated and noncoated vesicles appear fused with the vesicular chain component of the MAC. $A$, A mitochondrion forms a MAC $(M)$ adjacent to a synapse $(s)$. The vesicular chain $(v c)$ leads into a branched tubular network adjacent to the mitochondrion, to which coated vesicles (solid arrows) appear fused. A coated vesicle at the synapse (open arrow) appears to be in the process of endocytosis. $B$, Two mitochondria form side-byside MACs $(M)$; the edge of a synapse $(s)$ is adjacent to one of the MACs. The vesicular chain forms a tubular or flattened structure to which vesicles appear fused (arrowheads). C, Coated vesicles (solid arrows) are located next to the vesicular chain and just inside the presynaptic membrane. $D$, A coated pit (open arrow) is located at the end of a membrane invagination, at the edge of the EES (asterisk is within glial process inside the EES), and near a MAC. E, $F$, Noncoated vesicles (arrowheads) appear fused to the vesicular chain, which appears flattened in $E$ and tubular, bending along the side of the mitochondrion (dotted arrow), in F. A coated vesicle (open arrow) appears to be in the final stage of budding from the presynaptic membrane. Scale bar (shown in $F$ for $A-F): 250 \mathrm{~nm}$.
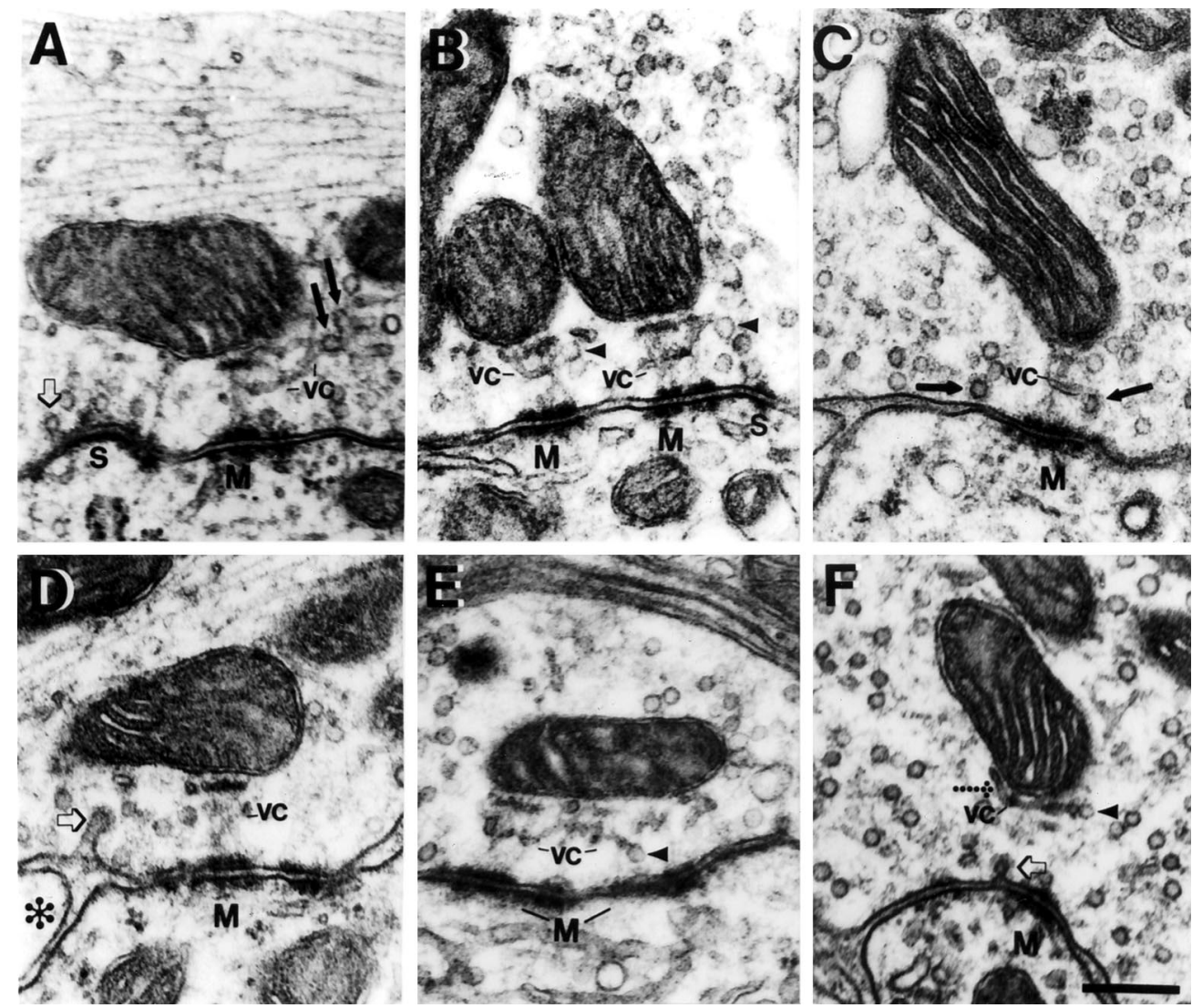

and forms two MACs (punctum adherens, green; mitochondrial plaque, orange) that are adjacent to synapses (red). The analysis of geometric complexity revealed distinct populations of mitochondria in the calyx. Most mitochondria did not form MACs and had two ends and were therefore vermiform in shape, although they may have a bend or curve along their length (Table 2). Mitochondria that formed MACs had a greater tendency to be complex ( $p<$ 0.001; Fisher's Exact Test), could form MACs along more than one process, and often had a process that extended away from the membrane into the core of the stalk or swelling (Fig. 2, m3; Fig. $5 F, G$, top limb of mitochondrion). Location of a mitochondrion within $200 \mathrm{~nm}$ of the presynaptic membrane, in a region of presynaptic and postsynaptic membrane apposition, was a strong predictor that it formed a MAC.

\section{Structural correlates of vesicle release probability}

The multitude of synapses in a single calyx and the requirement for the calyx to transmit high rates of activity to the MNTB cell may dictate that not all synapses release a vesicle with each invading action potential. MAC-associated synapses may have greater capacity to sustain vesicle release during the later stages of a spike train. The number of synaptic vesicles that are in position to be released is thought to be the structural equivalent of the readily releasable pool (von Gersdorff et al., 1996; Schikorski and Stevens, 1997). We counted in serial sections the number of synaptic vesicles that were docked in calyceal synapses to determine whether MACassociated synapses have a greater number of docked vesicles. Synaptic vesicles were classified as docked if there was no resolvable distance between their membrane and the presynaptic membrane or dense projections of the synaptic junction (Fig. $6 A$ ). There was no difference in the mean number of docked synaptic vesicles in MAC-associated synapses $(2.6 \pm 1.71)$ from those synaptic junctions positioned farther $(>500 \mathrm{~nm})$ from the MAC $(2.6 \pm 1.5)$, and therefore their distributions are combined (Fig. 6B). The low-calcium transcardial rinse that we used may have stopped vesicle fusion before fixation, but perhaps permitted reloading of vesicle docking sites in both MAC-associated and MAC- independent synapses. Using the estimate that each action potential evokes release of 0.2 of the readily releasable synaptic vesicle pool (Schneggenburger et al., 1999), we suggest that synapses having three or more docked vesicles are most likely to release a quantum of neurotransmitter upon depolarization (Fig. $6 B$, rightmost portion of distribution). Multiplying our distribution of the docked vesicles per synapse by our estimate of the number of synaptic junctions in the calyx, we calculate that the calyx contains 6200 readily releasable synaptic vesicles. Although the number of docked vesicles per synapse is a factor of 5-7 lower in the calyx than in hippocampal boutons (Harris and Sultan, 1995; Schikorski and Stevens, 1997), the great majority of hippocampal boutons contain only one active site. The large number of synapses in the calyx terminal may provide enough of a safety net that limits the rate at which individual synapses need to refill their docking sites, especially if the released fraction of vesicles declines during a spike train. Investigation of the effects of stimulus history on vesicle priming will require development of an in vitro preparation with appropriate ultrastructure preservation that permits counting of docked vesicles.

\section{DISCUSSION}

Our fundamental finding is that the MAC is intertwined with synapses and is found in the prototypical fast, glutamatergic nerve terminal, the calyx of Held. Because of its proximity to synapses and the component organelles from which it is constructed, we hypothesize that the MAC plays a central role in high rate, temporally precise neurotransmission that is a hallmark of the calyx terminal (Guinan and Li, 1990). The presence of coated, presumably endocytosing, vesicles adjacent to fusion sites and in locations encircling MAC/synapse clusters suggests that the calyx is composed of multiple activity zones, each being an engine for releasing and recharging its vesicle store. Increasingly, evidence points to a central role for mitochondria in regulating exocytosis on a fast time scale (Kaftan et al., 2000) (see below). The MAC is the most highly ordered structural arrangement of which we are aware, linking 

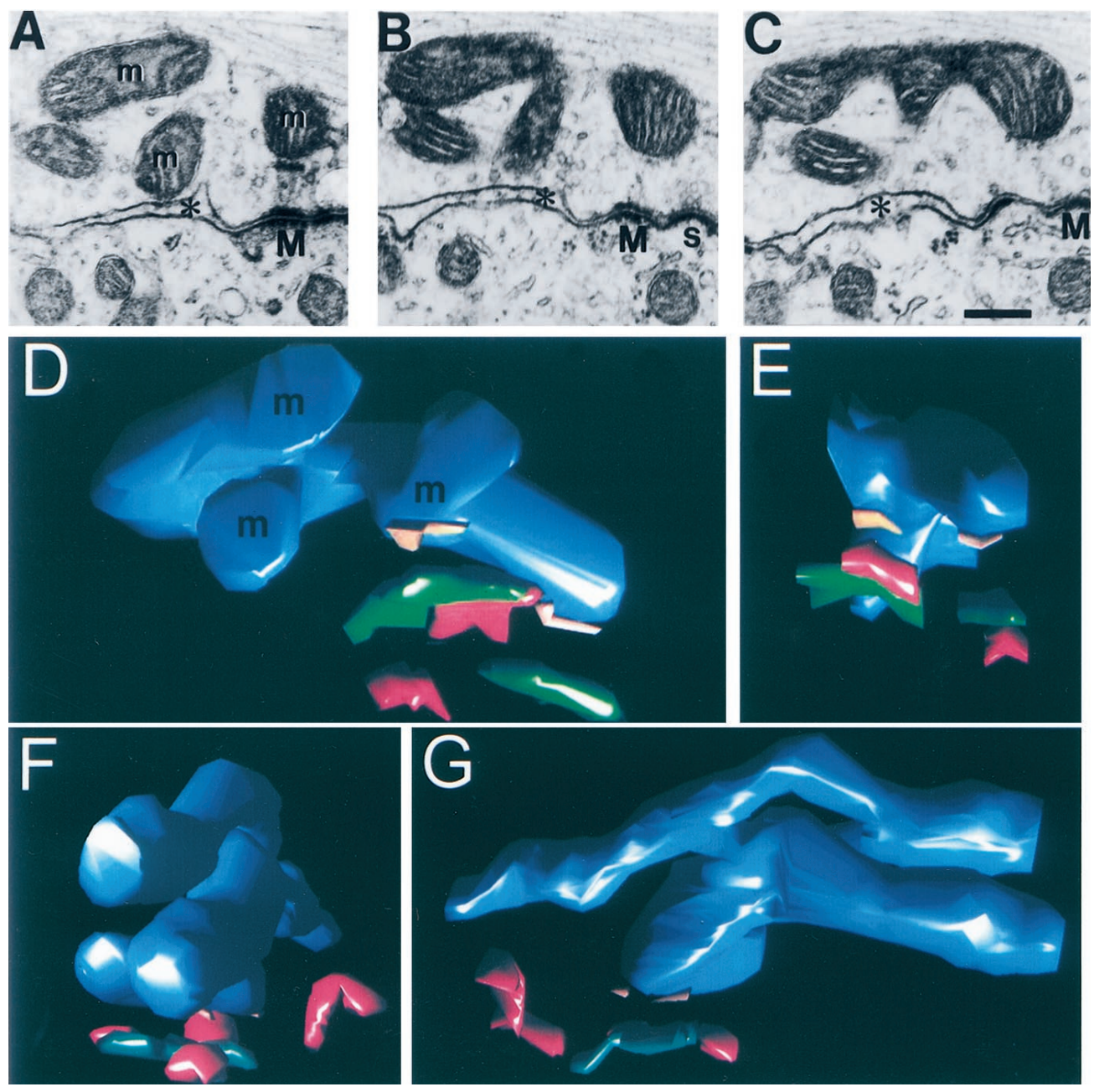

Table 2. Structural complexity of mitochondria

Mitochondria with two ends (tubular) two ends (complex)

Non-MAC forming

MAC forming

117

55
Percentage of mitochondria with more than two ends*

*Percentages were significantly different; Fisher's Exact Test $(p<0.001)$.

mitochondria to synaptic junctions, and it may play an integral role in synaptic transmission in the calyx.

\section{Auditory brainstem circuits}

The presence of MACs in end-bulbs and modified end-bulbs of Held in the cochlear nucleus (Cant and Morest, 1979; Tolbert and Morest, 1982), in large collateral terminals of calyceal axons in the superior olive (Spirou et al., 1998), and in calyces of Held implies their importance in neural circuits that subserve the early stages of sound localization (Fig. 7A). MAC-containing end-bulbs activate spherical bushy cells (Cant and Morest, 1979), which excite binaural cells of the medial superior olive (MSO) bilaterally and lateral superior olive ipsilaterally. MAC-containing modified end-bulbs activate globular bushy cells (Tolbert and Morest, 1982), which in turn excite ipsilateral cells of the lateral nucleus of the trapezoid body (LNTB) via MAC-containing modified end-bulbs (Spirou et al., 1998) and contralateral cells of the MNTB via calyces (now shown to also contain MACs). LNTB cells provide inhibitory input to the MSO (our unpublished data), and MNTB cells inhibit cells of the MSO and LSO (Moore and Caspary, 1983; Smith, 1995). Therefore, MAC-containing terminals drive both excitatory and inhibitory inputs to binaural comparator neurons.
Figure 5. Mitochondria can form more than one MAC and have complex geometry. $A-C$, Three limbs of a single, MACforming mitochondrion $(m)$. One MAC $(M)$ and its adjacent synapse $(s)$ are pictured. Asterisks indicate EES. Scale bar, $250 \mathrm{~nm}$. $D, E$, Orthogonal views of a three-dimensional reconstruction of the complex mitochondrion pictured in $A-C$. The mitochondrion (blue), mitochondrial plaques (orange bars), puncta adherentia (green), and synapses (red) are depicted. $F, G$, Three-dimensional reconstruction of a second complex mitochondrion (end and side views) with its associated MAC and synaptic structures. The two long limbs of this mitochondrion extend $>1$ $\mu \mathrm{m}$ in length.
MACs are also present in rat calyces of Held (our unpublished data) [also see Casey and Feldman (1985), their Figs. 5, 8, 19, 20, 22 , although the presence of MACs was not noted by these authors], but their prominence and association with synapses has not been determined. MACs have been described in terminals of some olivo-cochlear fibers that project from cells of the superior olive onto cell bodies of spiral ganglion neurons [monkeys: Kimura et al. (1987; humans: Rask-Andersen et al. (2000)]. It is not known whether these olivo-cochlear neurons generate high rates of temporally synchronous activity, in common with other MACcontaining auditory system neurons. The only other report of MACs of which we are aware is by Gray (1963) in his original description of this structure in the spinal cord. The cell type giving rise to nerve terminals containing MACs was not determined, nor have we found subsequent descriptions of this structure in more recent studies of the spinal cord. Structures bearing similarity to MACs, called filamentous contacts, have been described in thalamic relay nuclei (Colonnier and Guillery, 1964; Lieberman and Spacek, 1997). However, filamentous contacts are segregated from most synapses in the terminal. They do exhibit a vesicular chainlike membrane (called agranular reticulum) located between mito- 

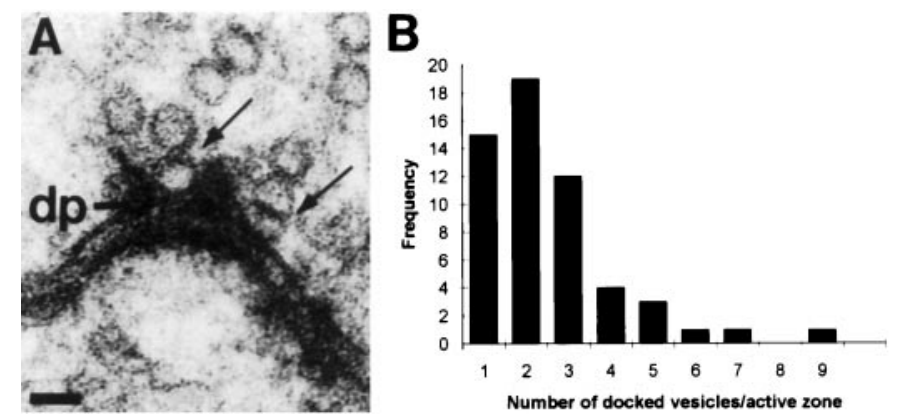

Figure 6. Synapses vary in the number of docked vesicles. $A$, Two synaptic vesicles (arrows) are docked at the presynaptic membrane, alongside hypothesized docking structures called dense projections $(d p)$. $B$, Distribution of the number of docked vesicles found in individual synapses. Mean number of docked vesicles is $2.53 \pm 1.61 ; n=56$.

chondria and the presynaptic punctum adherens. The mitochondrial cristae are less strictly oriented than in the MAC and occasionally filaments extend from the reticular membrane to the punctum adherens, but there is no mitochondrial plaque. Filamentous contacts feature a similar network of punctum adherens, filaments, and reticulum in the postsynaptic cell, incorporate tight junctions, and are also found at dendrodendritic and somasomatic junctions. They most likely play roles in intercellular communication that are distinct from MACs.

\section{Vesicle recycling and the readily releasable pool}

The vesicular chain component of MACs and synapses points to roles in vesicle membrane recycling. Generally two modes of vesicle recycling are thought to occur at nerve terminals: full fusion of vesicles with the presynaptic membrane followed by clathrinmediated endocytosis (Heuser and Reese, 1973) and partial fusion of vesicle membrane followed by rapid, clathrin-independent disassociation from the presynaptic membrane (also known as "kissand-run") (Ceccarelli et al., 1973; for review, see von Gersdorff and Matthews, 1999). Clathrin-coated endocytotic vesicles may fuse with endosomal intermediates that bud new synaptic vesicles, but recent evidence indicates that fusion with endosomes may not be part of the life cycle of the vesicle (Murthy and Stevens, 1998), even in the case of clathrin-coated vesicles (Takei et al., 1996). Coated vesicles are a common feature in calyx terminals and bud from synaptic zones, but more frequently from edges of the EES that form a border around MAC-synapse clusters. Coated vesicles are frequently located near and sometimes appear fused with the vesicular chain component of the MAC, so recycling through endosomal intermediates may support replenishment of vesicle stores in the calyx of Held. Therefore in the calyx the distinction between recycling and reserve (to sustain high activity rates) vesicle pools may be blurred (Kuromi and Kidokoro, 1999). Kiss-andrun may also be at play in calyx terminals but cannot be resolved with certainty using electron microscopy.

The calyx, like many other central synapses, exhibits frequencydependent synaptic depression that is caused mainly by depletion of the readily releasable pool of synaptic vesicles (Borst et al., 1995; von Gersdorff and Matthews, 1997; Wang and Kaczmarek, 1998). In rats, the readily releasable pool size in the calyx was estimated to be 700 vesicles (Schneggenburger et al., 1999). Using docked vesicles as a morphological indicator, we estimate that 6200 vesicles constitute the readily releasable pool in calyces, which may reflect the larger size of calyces in cats than in rats.

\section{Hypothesized functions of the MAC}

The conglomerate elements of the MAC result in a structure that, because of its uniqueness, is somewhat enigmatic in nature. In this section we offer several hypotheses (schematized in Fig. 7B) about the function of several MAC components and characteristics as a framework for investigating MAC functions in large auditory system nerve terminals.

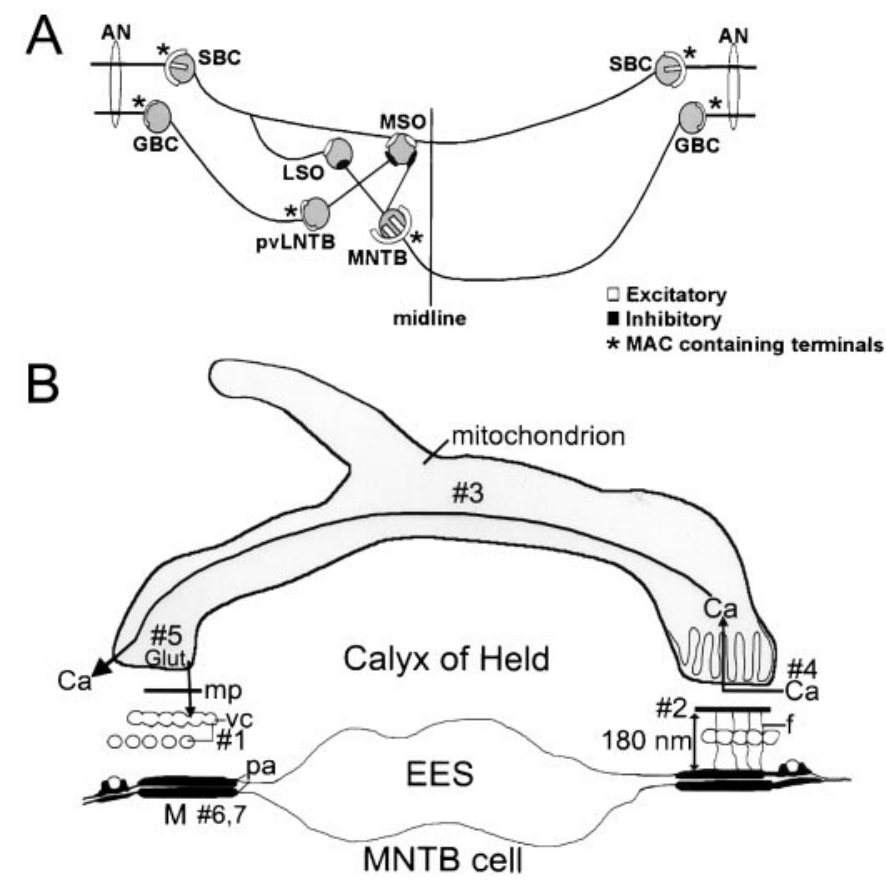

Figure 7. Auditory brainstem circuitry. $A$, Auditory nerve $(A N)$ fibers end in large, MAC-containing nerve terminals $(*)$ onto spherical $(S B C)$ and globular $(G B C)$ bushy cells of the cochlear nucleus. GBCs project ipsilaterally, via MAC-containing modified end-bulbs (*), to cells of the posteroventral lateral nucleus of the trapezoid body ( $p v L N T B)$ and contralaterally, via MAC-containing calyces $(*)$, to cells of the medial nucleus of the trapezoid body $(M N T B)$. Cells of the medial superior olive $(M S O)$ and lateral superior olive $(L S O)$ compare bilateral excitatory (from spherical bushy cells) and inhibitory (from LNTB and MNTB cells) inputs to assign a location to a sound source in space. $B$, Hypothesized functions of the MAC $[M$; composed of a mitochondrial plaque $(m p)$, vesicular chain $(v c)$, filaments $(f)$, punctum adherens $(p a)$, and a mitochondrion]. MNTB postsynaptic cell is at bottom; EES, extended extracellular space. Hypotheses: \#1, The vesicular chain is a reservoir for newly formed synaptic vesicles. \#2, The close proximity of mitochondria to the presynaptic membrane allows for calcium buffering at synapses. \#3, Calcium $(C a)$ is shuttled through the mitochondrion to other active zones of the terminal. \#4, Orientation of cristae facilitates calcium diffusion. \#5, Mitochondria support neurosecretion by manufacture of glutamate (Glut) neurotransmitter and refilling synaptic vesicles. \#6, Stabilization of the presynaptic membrane during high rates of activity is achieved by the punctum adherens. \#7, Puncta adherentia determine tonotopic innervation of the MNTB during development.

\section{Vesicular chain}

Recovery from synaptic depression of postsynaptic current amplitude is more rapid at high rates of stimulation at calyceal and hippocampal synapses (Stevens and Wesseling, 1998; Wang and Kaczmarek, 1998). Despite the reduced amplitude of postsynaptic currents, postsynaptic action potentials are reliably generated in brain slices at stimulus rates exceeding $500 \mathrm{~Hz}$ (Wu and Kelly, 1993). We hypothesize (Fig. 7B, \#1) that vesicular chain membrane provides a reservoir for rapid formation of new vesicles under conditions of sustained, high rates of activity.

\section{Mitochondrion, mitochondrial plaque, and filaments: a system to regulate calcium levels}

In the calyx, multiple calcium channels open to induce the release of single quanta, so the calcium load on the terminal can be very high (Borst and Sakmann, 1999a). Accumulating evidence indicates that mitochondria in nerve terminals, especially those nearest the synapse, increase their calcium conductance and sequester calcium during a train of impulses (David et al., 1998; Jonas et al., 1999; Pivovarova et al., 1999; Zenisek and Matthews, 2000). Activity-dependent changes in presynaptic calcium concentration can reach 5-10 $\mu \mathrm{M}$ at $200 \mathrm{~nm}$ from the synapse (Neher, 1998) and are likely detected by the mitochondrial component of the MAC, tethered at about that distance. Indeed, immediately after tetanic 
pulse trains, recovery from depression in the calyx is independent of membrane calcium currents (Forsythe et al., 1998) and may be caused in part by calcium re-release from MAC components. We hypothesize (Fig. $7 B, \# 2$ ) that the mitochondrial (and perhaps vesicular chain) components of the MAC are positioned precisely by the mitochondrial plaque and filaments to cooperate with other calcium-buffering entities in the terminal. Proper calcium buffering will affect facilitation or depression of vesicle release during successive action potentials (Forsythe et al., 1998; Bellingham and Walmsley, 1999; Borst and Sakmann, 1999b; Wu and Borst, 1999).

\section{Mitochondrial geometry and cristae: an intracellular conduit for calcium movement}

Mitochondria most likely participate with endosomal structures, such as endoplasmic reticulum, in an elaborate calcium-buffering network that can shuttle calcium signals through the cytoplasm within organelles (Babcock et al., 1997; Rizzuto et al., 1998). We hypothesize (Fig. $7 B, \# 3$ ) that the complex geometry of many MAC-associated mitochondria, perhaps together with the vesicular chain, may subserve this function, shuttling calcium from one activity module across the EES to another activity module and thereby affecting release probability at synapses several micrometers away. Furthermore, we propose (Fig. $7 B$, \#4) that the cristae of MAC-associated mitochondria are oriented perpendicular to the membrane to facilitate diff usion away from the synaptic region to other ends of the mitochondrion. Cristae of neuronal mitochondria can form lamellar, rather than tubular, structures (Perkins et al., 1997) that should have high capacity for calcium diffusion.

\section{Mitochondrial biochemistry: possible source of energy and neurotransmitter}

Tethering mitochondria near synaptic structures may link the upregulation of Krebs' cycle enzymatic activity by calcium to increased ATP production (Denton and McCormack, 1980) to support synaptic mechanisms activated by neural activity. Also, mitochondria can manufacture glutamate from $\alpha$-ketoglutarate, which in pancreas has a direct effect on insulin secretion (Maechler and Wollheim, 1999). We hypothesize (Fig. 7B, \#5) that MACassociated mitochondria may manufacture glutamate for use as a neurotransmitter, which is then used to refill recycled synaptic vesicles (Maycox et al., 1988).

\section{Punctum adherens: synaptic stabilization and development}

We have hypothesized previously (Fig. 7B, \#6) that the punctum adherens component of the MAC provides needed stability to the calyx-MNTB neuron contact to sustain high rates of neural activity and high-capacity membrane recycling (Spirou et al., 1998). The punctum adherens component of the MAC may play an additional role during early formation of the synapse. The cadherin protein family may be sufficiently diverse (Kohmura et al., 1998; Brose, 1999; Serafini, 1999) to underlie the tonotopic pattern by which calyceal growth cones innervate the appropriate MNTB cells to preserve this fundamental organizing principle of auditory neural circuits (Fig. 7B, \#7). A similar role in forming retinotopic connections was proposed for filamentous contacts (Colonnier and Guillery, 1964). The development of suitable experimental preparations and probes will form the basis for investigating these and other hypotheses about functions of this atypical organelle assembly.

\section{REFERENCES}

Babcock DF, Herrington J, Goodwin PC, Park YB, Hille B (1997) Mitochondrial participation in the intracellular $\mathrm{Ca}^{2+}$ network. $\mathrm{J}$ Cell Biol 136:833-844.

Bellingham MC, Walmsley B (1999) A novel presynaptic inhibitory mechanism underlies paired pulse depression at a fast central synapse. Neuron 23:159-170.

Berrebi AS, Mugnaini E (1991) Distribution and targets of the cartwheel cell axon in the dorsal cochlear nucleus of the guinea pig. Anat Embryol 183:427-454.

Berrebi AS, Spirou GA (1998) PEP-19 immunoreactivity in the cochlear nucleus and superior olive of the cat. Neuroscience 83:535-554.
Borst JG, Sakmann B (1999a) Depletion of calcium in the synaptic cleft of a calyx-type synapse in the rat brainstem. J Physiol (Lond) 521:123-133.

Borst JG, Sakmann B (1999b) Effect of changes in action potential shape on calcium currents and transmitter release in a calyx-type synapse of the rat auditory brainstem. Philos Trans R Soc Lond B Biol Sci 354:347-355.

Borst JG, Helmchen F, Sakmann B (1995) Pre- and postsynaptic wholecell recordings in the medial nucleus of the trapezoid body of the rat. J Physiol (Lond) 489:825-840.

Brose N (1999) Synaptic cell adhesion proteins and synaptogenesis in the mammalian central nervous system. Naturwissenschaften 86:516-524.

Cant NB, Morest DK (1979) The bushy cells in the anteroventral cochlear nucleus of the cat. A study with the electron microscope. Neuroscience 4:1925-1945.

Casey MA, Feldman ML (1985) Aging in the rat medial nucleus of the trapezoid body. II. Electron microscopy. J Comp Neurol 232:401-413.

Ceccarelli B, Hurlbut WP, Mauro A (1973) Turnover of transmitter and synaptic vesicles at the frog neuromuscular junction. J Cell Biol 57:499-524.

Colonnier M, Guillery RW (1964) Synaptic organization in the lateral geniculate nucleus of the monkey. $\mathrm{Z}$ Zellforsch Mikrosk Anat 62:333-355.

David G, Barrett JN, Barrett EF (1998) Evidence that mitochondria buffer physiological $\mathrm{Ca}^{2+}$ loads in lizard motor nerve terminals. J Physiol (Lond) 509:59-65.

Denton RM, McCormack JG (1980) The role of calcium in the regulation of mitochondrial metabolism. Biochem Soc Trans 8:266-268.

Fekete DM, Rouiller EM, Liberman MC, Ryugo DK (1984) The central projections of intracellularly labeled auditory nerve fibers in cats. J Comp Neurol 229:432-450.

Forsythe ID, Tsujimoto T, Barnes-Davies M, Cuttle MF, Takahashi T (1998) Inactivation of presynaptic calcium current contributes to synaptic depression at a fast central synapse. Neuron 20:797-807.

Gray EG (1963) Electron microscopy of presynaptic organelles of the spinal cord. J Anat Lond 97:101-106.

Guinan Jr JJ, Li RY (1990) Signal processing in brainstem auditory neurons which receive giant endings (calyces of Held) in the medial nucleus of the trapezoid body of the cat. Hear Res 49:321-334.

Gulley RL, Landis DMD, Reese TS (1978) Internal organization of membranes at end bulbs of Held in the anteroventral cochlear nucleus. J Comp Neurol 180:707-741.

Harris KM, Sultan P (1995) Variation in the number, location and size of synaptic vesicles provides an anatomical basis for the nonuniform probability of release at hippocampal CA1 synapses. Neuropharmacology 34:1387-1395.

Held H (1893) Die centrale Gehorleitung. Archiv für Anatomie und Physiologie. Anat Abt 201-248.

Heuser JE, Reese TS (1973) Evidence for recycling of synaptic vesicle membrane during transmitter release at the frog neuromuscular junction. J Cell Biol 57:315-344.

Jean-Baptiste M, Morest DK (1975) Transneuronal changes of synaptic endings and nuclear chromatin in the trapezoid body following cochlear ablations in cats. J Comp Neurol 162:111-134.

Jonas EA, Buchanan J, Kaczmarek LK (1999) Prolonged activation of mitochondrial conductances during synaptic transmission. Science 286:1347-1350.

Joris PX, Carney LH, Smith PH, Yin TC (1994a) Enhancement of neural synchronization in the anteroventral cochlear nucleus. I. Responses to tones at the characteristic frequency. J Neurophysiol 71:1022-1036.

Joris PX, Smith PH, Yin TC (1994b) Enhancement of neural synchronization in the anteroventral cochlear nucleus. II. Responses in the tuning curve tail. J Neurophysiol 71:1037-1051.

Kaftan EJ, Xu T, Abercrombie RF, Hille B (2000) Mitochondria shape hormonally-induced cytoplasmic calcium oscillations and modulate exocytosis. J Biol Chem 275:25465-25470.

Kimura RS, Bongiorno CL, Iverson NA (1987) Synapses and ephapses in the spiral ganglion. Acta Otolaryngol [Suppl] 438:1-18.

Kohmura N, Senzaki K, Hamada S, Kai N, Yasuda R, Watanabe M, Ishii H, Yasuda M, Mishina M, Yagi T (1998) Diversity revealed by a novel family of cadherins expressed in neurons at a synaptic complex. Neuron 20:1137-1151.

Kuromi H, Kidokoro Y (1999) The optically determined size of exo/endo cycling vesicle pool correlates with the quantal content at the neuromuscular junction of Drosophila larvae. J Neurosci 19:1557-1565.

Lenn NJ, Reese TS (1966) The fine structure of nerve endings in the nucleus of the trapezoid body and the ventral cochlear nucleus. Am J Anat 118:375-389.

Lieberman AR, Spacek J (1997) Filamentous contacts: the ultrastructure and three-dimensional organization of specialized non-synaptic interneuronal appositions in thalamic relay nuclei. Cell Tissue Res 288:43-57.

Maechler P, Wollheim CB (1999) Mitochondrial glutamate acts as a messenger in glucose-induced insulin exocytosis. Nature 402:685-689.

Maycox PR, Deckwerth T, Hell JW, Jahn R (1988) Glutamate uptake by brain synaptic vesicles. Energy dependence of transport and functional reconstitution in proteoliposomes. J Biol Chem 263:15423-15428.

Moore MJ, Caspary DM (1983) Strychnine blocks binaural inhibition in lateral superior olivary neurons. J Neurosci 3:237-242.

Morest DK (1968) The collateral system of the medial nucleus of the 
trapezoid body of the cat, its neuronal architecture and relation to the olivo-cochlear bundle. Brain Res 9:288-311.

Murthy VN, Stevens CF (1998) Synaptic vesicles retain their identity through the endocytic cycle. Nature 392:497-501.

Nakajima Y (1971) Fine structure of the medial nucleus of the trapezoid body of the bat with special reference to two types of synaptic endings. J Cell Biol 50:121-134.

Neher E (1998) Vesicle pools and $\mathrm{Ca}^{2+}$ microdomains: new tools for understanding their roles in neurotransmitter release. Neuron 20:389-399.

Perkins G, Renken C, Martone ME, Young SJ, Ellisman M, Frey T (1997) Electron tomography of neuronal mitochondria: three-dimensional structure and organization of cristae and membrane contacts. J Struct Biol 119:260-272.

Petelina EV (1975) Ultrastructure of synapses in the nucleus of the trapezoid body of the bat. Arkh Anat Gistol Embriol 68:14-18.

Pivovarova NB, Hongpaisan J, Andrews SB, Friel DD (1999) Depolarization-induced mitochondrial $\mathrm{Ca}$ accumulation in sympathetic neurons: spatial and temporal characteristics. J Neurosci 19:6372-6384.

Rask-Andersen H, Tylstedt S, Kinnefors A, Illing R (2000) Synapses on human spiral ganglion cells: a transmission electron microscopy and immunohistochemical study. Hear Res 141:1-11.

Rizzuto R, Pinton P, Carrington W, Fay FS, Fogarty KE, Lifshitz LM

Tuft RA, Pozzan T (1998) Close contacts with the endoplasmic reticulum as determinants of mitochondrial $\mathrm{Ca}^{2+}$ responses. Science 280:1763-1766.

Ryugo DK, Wu MM, Pongstaporn T (1996) Activity-related features of synapse morphology: a study of endbulbs of Held. J Comp Neurol 365:141-158.

Schikorski T, Stevens CF (1997) Quantitative ultrastructural analysis of hippocampal excitatory synapses. J Neurosci 17:5858-5867.

Schneggenburger R, Meyer AC, Neher E (1999) Released fraction and total size of a pool of immediately available transmitter quanta at a calyx synapse. Neuron 23:399-409.

Serafini T (1999) Finding a partner in a crowd: neuronal diversity and synaptogenesis. Cell 98:133-136.

Smith PH (1995) Structural and functional differences distinguish principal from nonprincipal cells in the guinea pig MSO slice. J Neurophysiol 73:1653-1667.

Smith PH, Joris PX, Carney LH, Yin TC (1991) Projections of physiologically characterized globular bushy cell axons from the cochlear nucleus of the cat. J Comp Neurol 304:387-407.
Smith PH, Joris PX, Yin TC (1998) Anatomy and physiology of principal cells of the medial nucleus of the trapezoid body (MNTB) of the cat. J Neurophysiol 79:3127-3142.

Spirou GA, Berrebi AS (1996) Organization of ventrolateral periolivary cells of the cat superior olive as revealed by PEP-19 immunocytochemistry and Nissl stain. J Comp Neurol 368:100-120.

Spirou GA, Brownell WE, Zidanic M (1990) Recordings from cat trapezoid body and HRP labeling of globular bushy cell axons. J Neurophysiol 63:1169-1190.

Spirou GA, Rowland KC, Berrebi AS (1998) Ultrastructure of neurons and large synaptic terminals in the lateral nucleus of the trapezoid body of the cat. J Comp Neurol 398:257-272.

Sternberger LA (1979) Immunocytochemistry, Ed 2. New York: Wiley.

Stevens CF, Wesseling JF (1998) Activity-dependent modulation of the rate at which synaptic vesicles become available to undergo exocytosis. Neuron 21:415-424.

Takei K, Mundigl O, Daniell L, De Camilli P (1996) The synaptic vesicle cycle: a single vesicle budding step involving clathrin and dynamin. J Cell Biol 133:1237-1250.

Tolbert LP, Morest DK (1982) The neuronal architecture of the anteroventral cochlear nucleus of the cat in the region of the cochlear nerve root: electron microscopy. Neuroscience 7:3053-3067.

von Gersdorff H, Matthews G (1997) Depletion and replenishment of vesicle pools at a ribbon-type synaptic terminal. J Neurosci 17:1919-1927.

von Gersdorff H, Matthews G (1999) Electrophysiology of synaptic vesicle cycling. Annu Rev Physiol 61:725-752.

von Gersdorff H, Vardi E, Matthews G, Sterling P (1996) Evidence that vesicles on the synaptic ribbon of retinal bipolar neurons can be rapidly released. Neuron 16:1221-1227.

Wang LY, Kaczmarek LK (1998) High-frequency firing helps replenish the readily releasable pool of synaptic vesicles. Nature 394:384-388.

Wu LG, Borst JG (1999) The reduced release probability of releasable vesicles during recovery from short-term synaptic depression. Neuron 23:821-832.

Wu SH, Kelly JB (1993) Response of neurons in the lateral superior olive and medial nucleus of the trapezoid body to repetitive stimulation: intracellular and extracellular recordings from mouse brain slice. Hear Res 68:189-201.

Zenisek D, Matthews G (2000) The role of mitochondria in presynaptic calcium handling at a ribbon synapse. Neuron 25:229-237. 